\title{
INCREASED LEVEL OF ADVANCED OXIDATION PRODUCTS (AOPP) AS A MARKER OF OXIDATIVE STRESS IN PATIENTS WITH ACUTE CORONARY SYNDROME
}

\author{
Marcela Škvařilováa , Adam Bulavaa, David Stejskal ${ }^{b}$, Sylva Adamovskáb, Josef Bartek ${ }^{\mathrm{c}}$
}

\author{
a $I^{\text {st }}$ Department of Internal Medicine, Teaching Hospital Olomouc, Czech Republic \\ ${ }^{b}$ Department of Laboratory Medicine, Hospital Šternberk, Czech Republic \\ c Institute of Medical Chemistry and Biochemistry, Faculty of Medicine, Palacký University, Hněvotínská 3, 775 15 Olomouc, \\ Czech Republic \\ e-mail:bartek@tunw.upol.cz
}

Received: April 7, 2005; Accepted (with revisions): June 3, 2005

Key words: Advanced oxidation protein products/Atherosclerosis/Coronary artery disease/Oxidative stress

Oxidative stress impairs endothelial function and may play an important role in the pathogenesis of acute cardiovascular diseases. Advanced oxidation protein products (AOPP) were proposed as one of the possible markers of oxidative injury, which originates under oxidative and carbonyl stress and increase global inflammatory activity.

The present study was undertaken to compare AOPP concentrations in a control group of healthy individuals without ICHS (I), patients with stable angina pectoris (II), patients with acute coronary syndrome over 48 hours without ST elevations (III), and patients with ST elevation myocardial infarction (IV).

Coronaronary angiography, risk factors and anamnestic data were analyzed. We examined 73 probands with signs of myocardial ischemia, mean age of 61.5 years ( $64 \%$ males) subjected to coronarography and 21 healthy individuals. No significant difference was found between venous blood and coronary samples, or between infarction and non-infarction arteries in the group IV. AOPP concentrations in healthy individuals in the group I (82.9 $\pm 29.3 \mathrm{mmol} / 1)$ did not differ significantly from patients in group II $(89.6 \pm 26.7 \mathrm{mmol} / 1)$ and group III $(112.3 \pm 54.6 \mathrm{mmol} / \mathrm{l})$. A significant difference in AOPP values was found between the groups I and IV, and between the groups II and IV $(82.9 \pm 29.3 \mathrm{mmol} / 1$ vs. $125.8 \pm 101 \mathrm{mmol} / 1, \mathrm{p}=0.02$, and $89.6 \pm 26.7 \mathrm{mmol} / 1 \mathrm{vs} .125 .8 \pm 101 \mathrm{mmol} / 1, \mathrm{p}=0.02)$. No correlations were found between AOPP and body mass index (BMI), nicotinism, left ventricular ejection fraction, parameters of glucose and lipid metabolism. ROC analysis revealed that AOPP concentrations of $89 \mathrm{mmol} / 1$ had $64 \%$ sensitivity and $71 \%$ specificity for revealing an acute coronary syndrome (AUC 0.65, 95\% CI 0.55-0.80).

AOPP are significantly increased in patients with acute coronary syndromes with ST segment elevation, but also tend to increase in patients with non-ST elevation myocardial infarction. Our observations suggest that AOPP may be used as a marker of oxidative stress and as a prognostic factor for severe forms of cardiovascular disease. A cut-off value of $89 \mathrm{mmol} / 1$ can be used with $64 \%$ sensitivity and $71 \%$ specificity for revealing acute coronary syndrome.

\section{INTRODUCTION}

Atherosclerosis is considered an immune-inflammatory (reparative) process induced by impaired intima of the vascular wall. The pathogenesis of the atherosclerotic process is multifactorial ${ }^{1}$ and the first step in this process may be endothelial dysfunction induced by dyslipidemia. Its progression is given by activation of cell and humoral components of the inflammation. Recently, oxidative stress has often been discussed as an important phenomenon. The stress is associated with the origination of free oxygen radicals that may impair cells and tissues. The relationship between oxidative stress and the pathophysiology of atherosclerosis remains unclear, but involvement of free oxygen radicals in acute coronary syndromes (ACS) is highly probable ${ }^{2,3}$.

At present, no generally applicable method for determination of free radicals in vivo is available. Recently, the importance of advanced oxidation protein products
(AOPP) has been pointed out ${ }^{4}$. These products originate as a result of the action of free radicals on proteins and may act as inflammatory mediators triggering the oxidative "ignition" of neutrophiles, monocytes and T-lymphocytes thus leading to upregulation and excessive stimulation of dendritic cells ${ }^{5}$. These processes may account for immune disorders in atherosclerosis. Kaneda et al showed that patients with ischemic heart disease (confirmed by coronarography) probably have similar increased AOPP values as dialysed patients and that concentrations of these products in both groups differ significantly from healthy volunteers $^{6,23}$.

More detailed knowledge of AOPP pathophysiology could provide very valuable information on the origin and development of atherosclerosis as well as on the relationship between oxidative stress and the origin of acute coronary syndrome.

As no data in the literature were found on AOPP concentrations in patients with acute coronary syndrome and 
patients with stable angina pectoris, the aim of the present study was to evaluate whether:

a) AOPP concentrations differ in patients with acute coronary syndrome from AOPP levels in patients with stable angina pectoris and from healthy individuals,

b) AOPP concentrations differ in venous blood and main coronary arteries,

c) AOPP concentrations differ in individuals with acute myocardial infarction in the infarction and the noninfarction artery,

d) correlations exist between AOPP concentrations and common risk factors of cardiovascular disease.

\section{MATERIALS AND METHODS}

We examined 73 probands, patients at the Angiography Center of the 1st Department of Internal Medicine, University Hospital Olomouc, who were subjected to coronarography according to common indication criteria, and 21 healthy individuals without clinical and anamnestic signs of coronary artery disease (CAD).

The examined persons were divided into 4 groups: Group I consisted of probands without CAD, group II comprised patients with stable angina, group III consisted of individuals with acute coronary syndrome over 48 hours without elevation of ST segment, and group IV comprised patients with acute myocardial infarction with elevated ST segments (STEMI) during the first 48 hours after origin and occlusion of the coronary artery confirmed during acute coronarography.

In all individuals, the following parameters were determined in peripheral venous blood: AOPP (according to Witko-Sarsat [3], ELISA line Marc+Max), cholesterol (enzyme, BioVendor), HDL (direct determination, BioVendor), triglycerides (enzyme, BioVendor), glucose (enzyme, Lachema), cTnI (LEIA, DPC), HbA1c (HPLC afinite boronate, Primus), creatinine (Jaffe), urea (enzyme, BioVendor), ALT (IFCC, BioVendor), AST (IFCC, BioVendor), CRP ultrasensitive (LEIA, DPC), blood count (Coulter).

Blood samples from the right and the left coronary arteries were collected in individuals subjected to coronarography and AOPP concentrations were determined. In coronary arteries we checked catheter insertion and then removed $5 \mathrm{ml}$ of blood from the catheter in order to prevent admixture of blood from the aorta, finally, 5-7 ml of blood from the coronary artery were collected for next analysis.

At the same time, the medical history of all individuals was taken with regard to cardiovascular risk factors, complications and therapy. Patients in groups II-IV were subjected to echocardiography and the left ventricular ejection fraction (LVEF) was calculated using the Simpson rule.

Coronarography was performed via the left femoral artery using the $6 \mathrm{~F}$ or $7 \mathrm{~F}$ instruments. An experienced invasive cardiologist assessed occlusion of the coronary artery and stenosis. All patients in the group II (stable angina pectoris) had at least one coronary artery stenosis narrowing the lumen by over $60 \%$ at coronarography.

All data were processed using the software SPSS for Windows. Continuous variables are expressed as mean \pm standard deviation unless stated otherwise. The levels of AOPP between groups were compared using repeated analysis of variance (ANOVA, Kruskal Wallis tests) and ROC analysis. Concentrations of AOPP and other quantities were mutually correlated using the Spearman correlation coefficient. Categorical data were compared using the $\chi^{2}$ test. A p value $<0.05$ was considered as statistically significant.

\section{RESULTS}

We examined altogether 94 probands of mean age 61.5 years (64\% males and $36 \%$ females). In $18 \%$ individuals we found heart failure, $21 \%$ had previous MI, $7 \%$ of patients underwent previous revascularization, $14 \%$ were active smokers, $71 \%$ were treated for hypertension and $29 \%$ for diabetes mellitus. Detailed data of patients under study are given in Table 1 .

Concentrations of AOPP in healthy individuals in control group I $(82.9 \pm 29.3 \mathrm{mmol} / \mathrm{l})$ did not differ markedly compared to patients in group II $(89.6 \pm 26.7 \mathrm{mmol} / \mathrm{l}$, $\mathrm{p}=\mathrm{NS})$ and group III $(112.3 \pm 54.6 \mathrm{mmol} / \mathrm{l}, \mathrm{p}=\mathrm{NS})$. Significant differences in AOPP values were found between the groups I and IV and groups II and IV, respectively $(82.9 \pm 29.3 \mathrm{mmol} / 1$ vs. $125.8 \pm 101 \mathrm{mmol} / 1, \mathrm{p}=0.02$, and $89.6 \pm 26.7 \mathrm{mmol} / 1$ vs. $125.8 \pm 101 \mathrm{mmol} / 1, \mathrm{p}=0.02$, respectively).

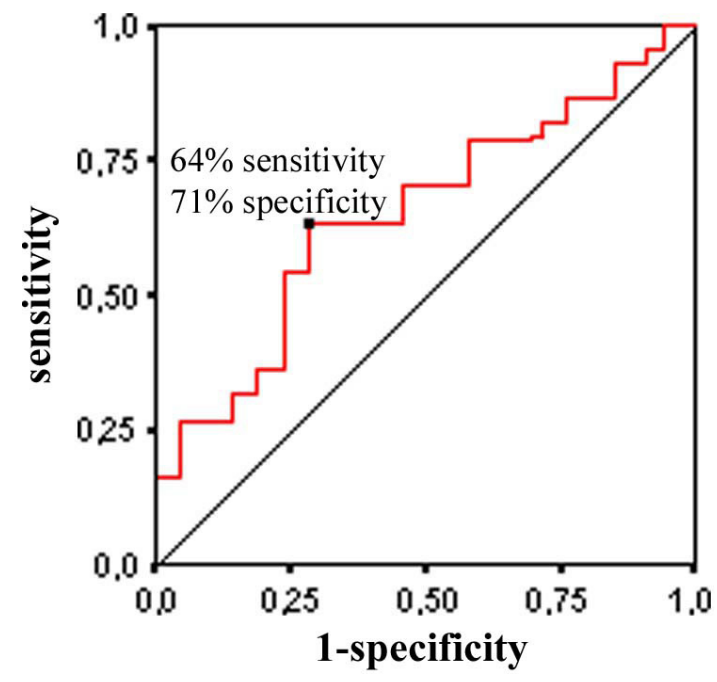

Fig. 1. ROC curve for the group I (healthy controls) and the group IV (patients with acute myocardial infarction with ST elevation within 48 hours after the onset of pain). Area under curve is 0.65 (95\% CI, $0.55-0.80)$. The straight line represents the line of identity. The level of AOPP $=89 \mathrm{mmol} / 1$ is given for maximal sensitivity (64\%) and specificity (71\%) 
Table 1. Clinical data of the groups I-IV.

\begin{tabular}{|l|c|c|c|c|}
\hline & Group I & Group II & Group III & Group IV \\
\hline $\mathrm{n}$ & 21 & 23 & 28 & 22 \\
\hline Age & $50 \pm 14$ & $62 \pm 10$ & $67 \pm 9$ & $66 \pm 9$ \\
\hline $\mathrm{M} / \mathrm{F}$ & $10 / 11$ & $15 / 8$ & $18 / 10$ & $15 / 7$ \\
\hline Dyslipidemia & $5(24 \%)$ & $15(65 \%)$ & $14(50 \%)$ & $8(36 \%)$ \\
\hline HN & $7(33 \%)$ & $20(87 \%)$ & $23(82 \%)$ & $17(77 \%)$ \\
\hline DM & $1(5 \%)$ & $8(35 \%)$ & $12(43 \%)$ & $6(27 \%)$ \\
\hline Smoker & $3(14 \%)$ & $1(4 \%)$ & $5(18 \%)$ & $4(18 \%)$ \\
\hline BMI & $23.9 \pm 3.5$ & $28.4 \pm 3.4$ & $28.9 \pm 3.5$ & $26.9 \pm 3.1$ \\
\hline Revascul. & 0 & $5(22 \%)$ & $1(4 \%)$ & $1(5 \%)$ \\
\hline
\end{tabular}

Table 2. Concentration of other studies markers in the group under study. Medians are given for each parameter.

\begin{tabular}{|l|c|c|c|c|c|c|c|c|c|c|c|}
\hline & chol & LDL & HDL & TG & ALT & urea & creat & HBA1c & CRP & BMI & EF \\
\hline Group I & 5.12 & 2.48 & 2.11 & 0.99 & 0.32 & 4.8 & 81.0 & - & 6.9 & 21.8 & 60 \\
\hline Group II & 5.12 & 2.83 & 1.19 & 2.15 & 0.41 & 5.8 & 97 & - & 2.0 & 27.3 & 58 \\
\hline Group III & 6.13 & 4.1 & 1.25 & 2.38 & 0.40 & 6.5 & 102 & 7.6 & 5.3 & 29.1 & 50 \\
\hline Group IV & 7.22 & 5.15 & 1.22 & 2.04 & 0.49 & 6.0 & 103 & 6.15 & 4.2 & 25.3 & 50 \\
\hline Total & 5.42 & 3.23 & 1.34 & 1.37 & 0.38 & 5.7 & 95 & 7.6 & 3.95 & 27.4 & 58 \\
\hline
\end{tabular}

It was shown that AOPP concentrations in peripheral venous blood and arterial blood from the coronary arteries did not differ markedly and showed a significant correlation $(\mathrm{r}=0.826, \mathrm{p}<0.0001)$.

In the groups III and IV no significant difference was found in AOPP concentrations in the infarction and the non-infarction arteries $(120.3 \pm 77.7 \mathrm{mmol} / 1$ vs. $122.6 \pm 78.8 \mathrm{mmol} / 1, \mathrm{p}=\mathrm{NS})$. Concentrations of other parameters under study are summarized in Table 2.

No correlations were observed between AOPP and BMI, history of nicotinism, left ventricular ejection fraction, parameters of glucose and lipid metabolism or nitrogen metabolites.

ROC analysis revealed that AOPP concentration of $89 \mathrm{mmol} / 1$ had $64 \%$ sensitivity and $71 \%$ specificity of revealing acute coronary syndrome (AUC $0.65,95 \% \mathrm{CI}$ 0.55-0.80) - Fig. 1.

\section{DISCUSSION}

Several recent papers point out the role of oxidative stress in acceleration of atherosclerosis. Stress is associated with the origin of a large number of free radicals that may impair cells and tissues. Free radicals are atoms or groups of atoms with an unpaired electron. They display high reactivity and during a very short time they are able to bind to lipoproteins, nucleic acids, proteins and enzymes. Free radicals comprise oxygen reactive forms (e.g. hydroxyl radical $\mathrm{OH}$ ), superoxide and peroxide ions $\mathrm{s}^{7,8}$. Binding of free radicals to nitrogen oxide (NO) in the endothelium leads to its reduced vasodilatation abilities accounting for the origin of coronary ischemia.

An important role in the origin of oxidative stress is assigned to xantinoxidase, NADPH oxidase, high concentration of oxidized LDL-cholesterol and delayed flow in the coronary artery ${ }^{9-11}$. Several factors involved in the origin of oxidative stress are combined. Important is the level of anti-oxidative protection of the organism ${ }^{12,13}$.

Recent papers suggest that AOPP is not only a marker of oxidative stress, but also acts as an inflammatory mediator ${ }^{4,24}$. Detailed investigation of AOPP is expected to provide valuable information on the origin and progression of atherosclerosis.

Kaneda et al published the results by measurement of AOPP in patients with CAD and showed that their AOPP values were significantly higher than those without $C A D$. This paper indicates that AOPP concentrations are re- 
lated to the extent of diseased coronary arteries. However, the association with the clinical state of patients remains unclear ${ }^{4}$. The results of our study suggest that patients with stable angina pectoris, i.e. patients with favorable prognosis, had no significantly higher AOPP concentrations compared to the control group of healthy individuals. We proved that AOPP concentration increases significantly only in patients with acute coronary syndrome.

The finding of no significant difference in AOPP concentrations between the infarction and the non-infarction arteries corresponds to a recent report on the presence of multiple vulnerable plates in all coronary arteries in patients with ACS and supports the idea of a "pan-coronary" process in contrast to the hypothesis of a single (culprit) lesion ${ }^{14,15}$. An association was shown between oxidative impairment of the arterial wall and the activity of myeloperoxidase and the group of metalloproteinase enzymes that are markedly involved in rupture of sclerotic plate as well as in the origin of acute coronary syndrome ${ }^{16,17}$.

In our study, no statistically significant correlations of AOPP levels with the commonly recognized cardiovascular risk factors were found. This may be due to a low number of individuals in each group.

Our study is handicapped by the fact that patients with acute coronary syndrome (groups III and IV) had not been followed for AOPP level dynamics. It is possible that the patients with STEMI may have had higher AOPP concentration after certain time interval from the onset of coronary artery closure. In addition, the concentrations of AOPP in patients with STEMI may have increased after opening of the coronary artery by angioplasty.

\section{CONCLUSION}

Concentrations of AOPP are associated with the extent of coronary artery impairment. AOPP values do not differ in the major coronary arteries and peripheral venous circulation. No difference in AOPP concentrations between the infarction and the non-infarction artery was found in patients with ST elevation myocardial infarction. Determination of AOPP appears to be a feasible and suitable marker of oxidative stress and may be used as a prognostic factor for severe forms of cardiovascular disease. A cut-off value of $89 \mathrm{mmol} / 1$ can be used with $64 \%$ sensitivity and $71 \%$ specificity for revealing acute coronary syndrome.

\section{ACKNOWLEDGEMENT}

Financial support by the Ministry of Education, Youth and Sport ( MSM 6198959216) is acknowledged.

\section{REFERENCES}

1. Cai H, Harrison DG (2000) Endothelial dysfunction in cardiovascular diseases: the role of oxidant stress. Circ Res 101, 840-844.

2. Leewenburgh C, Hardy MM, Hazen SL. (1997) Reactive nitrogen intermediates promote low density lipoprotein oxidation in human atherosclerotic intima. J Biol Chem 272, 1433-1436.

3. Witko-Sarsat V, Friedlander M, Capeiller-Blandin C. (1996) AOPP as a novel marker of oxidative stress in uremia. Kidney Int 49, 1304-1313.

4. Seljelflot I, Aase O, Eid H. (2002) Levels of oxidative stress are associated with C-reactive protein levels in patients with stable and unstable angina. Europ Heart J 4, 298-306.

5. Alderman Ch J J, Shah S, Foreman JC. (2002) The role of advanced oxidation protein products in regulation od dendritic cell function. Free Radical Biol Med 32, 377-385.

6. Kaneda H, Taguchi J, Ogasawara K. (2002) Increased level of advanced oxidation protein products in patients with coronary artery disease. Atherosclerosis 162, 221-225.

7. Warnholtz A, Nickenig G, Schulz E. (1999) Increased NADH-oxidase mediated superoxid production in the early stages of atherosclerosis: evidence for involvement of the renin-angiotensin sytem. Circulation 99, 2027-2033.

8. Leewenburgh C, Hardy MM, Hazen SL. (1997) Mass spectrometric quantification of markers for protein oxidation by tyrosyl radical, copper, end hydroxyl radical in low density lipoprotein isolated from human atheroscelrotic plaques. J Biol Chem 272, 3520-3526.

9. Sorescu D, Weiss MD, Lassege B. (2002) Superoxide Production and Expression of Nox Family Proteins in human atherosclerosis. Circulation 105, 1429-1435.

10. Npjiri S, Daida H, Mokuno H. (2001) Association of serum antioxidant capacity with CAD in middle-aged men. Jpn Heart J 42, 677-690.

11. Bobak M, Brunner E, Miller NJ. (1998) Could antioxidants play a role in the high rates of coronary heart disease in the Czech Republic? Eur J Clin Nutr 52, 632-636.

12. Descamps-Latscha B, Drueke T, Witko-Sarsat V. (2001) Dialysisinduced oxidative stress:biological aspects, clinical consequences, and therapy. Semin Dial 14, 193-199.

13. Goldstein JA, Demetriou BD, Grines CL. (2000) Multiple complex coronary plaques in patients with acute myocardial infarction. N Engl J Med 343, 915-922.

14. Descamps-Latscha B, Witko-Sarsat V. (2001) Importance of oxidatively modified proteins in chronic renal failure. Kidney Int Suppl $78,103-113$.

15. Descamps-Latscha B, Jungers P, Witko-Sarsat V. (2002) Immune system dysregularton in uremia: role of oxidative stress. Blood Purif 20, 481-484

16. Kalousova M, Fialova L, Zima T, Malbohan IM. (2002) Advanced oxidation protein products in pregnancy. Ceska Gynekol 67, 194197.

17. Drucke T, Witko-Sarsat V, Massy Z. (2002) Iron therapy, AOPP, and carotid artery IMT in end-stage renal disease. Circulation 106, 2212-2217.

18. Alderman CJ, Shah S, Foreman JC. (2002) The role of AOPP in regulation of dendritic cell function. Free Radic Biol Med 32, 377-385.

19. Buonocore G, Perrone S, Longini M. (2002) Oxidative stress in preterm neonates at birth and on the seventh day of life. Pediatr Res $52,46-49$.

20. Kalousova M, Skrha J, Zima T. (2002) Age and AOPP in patients with diabetes mellitus. Physiol Res 51, 597-604.

21. Matteucci E, Biasi E, Giampietro O. (2001) AOPP in plasma: stability during storage and correlation with other clinical characteristics. Acta Diabetologica 38, 187-190.

22. Zima T. (1999) Metody detekce poškození organismu volnými radikály. Labor Aktuell-CS 2, 9-13.

23. Kalousova M, Zima T, Tesar V, Sulkova S, Fialova L. (2003) Relationship between advanced glycoxidation end products, inflam- 

with acute coronary syndrome

matory markers/acute-phase reactants, and some autoantibodies in chronic hemodialysis patients. Kidney Int Suppl 84, 62-64.

24. Witko-Sarsat V, Gausson V, Descamps-Latscha B. (2003) Are advanced oxidation protein products potential uremic toxins? Kidney Int Suppl 84, 11-14.
25. Sebekova K, Gazdikova K, Syrova D, Blazicek P, Schinzel R, Heidland A, Spustova V, Dzurik R. (2003) Effects of ramipril in nondiabetic nephropathy: improved parameters of oxidatives stress and potential modulation of advanced glycation end products. $\mathrm{J}$ Hum Hypertens 7, 265-27. 